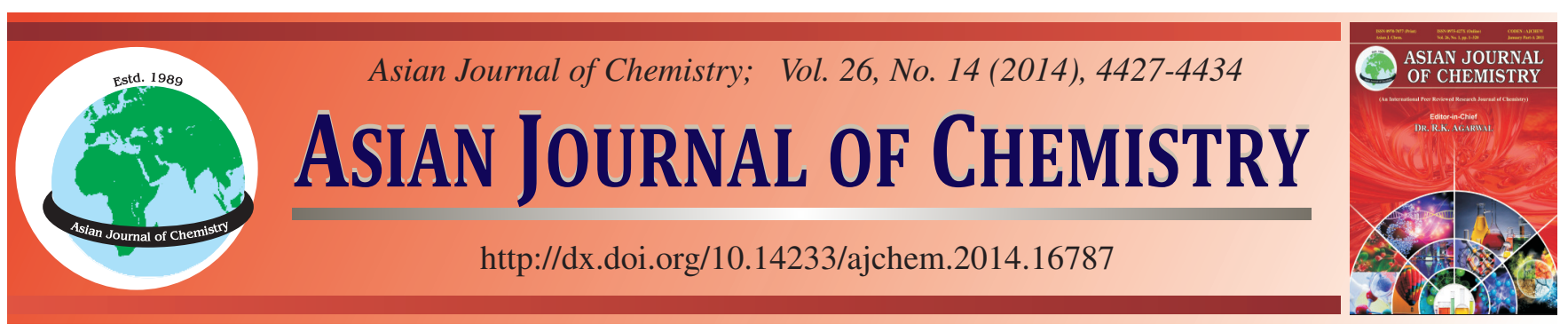

\title{
Water Quality Responses to Accumulation of Microcystis During Cyanobacterial Bloom Event in Different Littoral Vegetation Zones of Lake Taihu, China
}

\author{
Su-Lin Xiang ${ }^{1,2}$, Meng-Yuan Zhu ${ }^{1}$, Guang-Wei Zhu ${ }^{1, *}$ and Hai Xu ${ }^{1}$
}

${ }^{1}$ State Key Laboratory of Lake Science and Environment, Nanjing Institute of Geography and Limnology, Chinese Academy of Sciences, Nanjing 210008, P.R. China

${ }^{2}$ Department of Environmental Engineering, East China JiaoTong University, Nanchang 330013, P.R. China

*Corresponding author: Fax: +86 25 57714759; Tel: +86 25 86882186; E-mail: gwzhu@ @iglas.ac.cn

Received: 29 November 2013;

Accepted: 17 April 2014;

Published online: 5 July 2014;

AJC-15489

\begin{abstract}
To investigate the effects of bloom accumulation on water quality in different lake vegetation zones, we studied the physicochemical properties and nutrient levels during a bloom event in lake Taihu, China, using high-frequency field observations in an open water control zone, a floating plant zone dominated by Trapa bispinosa and Nymphoides peltatum and an emergent vegetation zone dominated by Phragmites australis. The results show that the emergent plant zone was much more susceptible to bloom accumulation. However, the bloom dispersed more slowly in the floating plant zone than in the emergent plant zone. At all sites, bloom accumulation led to significant increases in total nitrogen, total phosphorus and dissolved nutrients concentrations. High levels of nutrients accumulated more readily and dispersed more slowly in the floating plant zone than in the emergent plant zone. In later stages of the observation, blooms retained and affect dissolved nutrients. Therefore, the degree of bloom accumulation and the effect of bloom decomposition on nutrient levels varied significantly in different littoral vegetation zones. Littoral vegetation type is an important indicator to algal blooms for the implementation of ecological restoration strategies
\end{abstract}

Keywords: Littoral zone, Algal bloom, Nutrients, Macrophyte type.

\section{INTRODUCTION}

The increasingly frequent algal and cyanobacterial blooms in many lakes around the world are largely attributable to eutrophication caused by a variety of environmental factors ${ }^{1-5}$. China's lake Taihu has suffered severely, with accumulations affecting large areas of the lake since the $1980 \mathrm{~s}^{6}$. Lake bloom formation is a complex hydro-biological phenomenon, influenced by temperature, light, hydrodynamics and nutrient conditions ${ }^{7}$. One of the most frequently problematic bloom species is Microcystis ${ }^{8,9}$. It accumulates in the littoral zones of shallow lakes and its distribution is often influenced by wind and local vegetation. Aquatic vegetation plays an important role in bloom accumulation and as such, can have profound effects on the biogeochemical cycling of nitrogen and phosphorus. During the growing season, plants are able to assimilate large quantities of nutrient, leading to decreases in the nutrient levels observed in sediment and water ${ }^{10,11}$. At other times, the decomposition of aquatic plants may increase nutrient levels in the water ${ }^{12,13}$.

Many investigations have focused on the response of harmful algal blooms to additions of nitrogen and phosphorus and on nitrogen/phosphorus ratios as limiting factors on bloom development ${ }^{14,15}$. However, relatively little attention has been paid to the effects of bloom accumulation on nutrient levels ${ }^{13,11}$ and relevant studies comparing the accumulation of blooms in different aquatic vegetation zones are more scarce. The understanding of the nature and mechanism of bloom formation and accumulation in different aquatic plants zones and consequent variations in water quality is urgently required.

Lake Taihu is the third largest freshwater lake in China at $2427.8 \mathrm{~km}^{2}$, but averages a mere $1.9 \mathrm{~m}$ deep being situated in a highly developed and densely populated area. It is an important source of water for drinking and irrigation, but rapid economic development and the intensive use of water resources have led to the lake become seriously polluted. Because of nutrient overload, Taihu is eutrophic ${ }^{16}$, with extensive algal bloom coverage persisting throughout the summer months and seriously affecting drinking water supplies. In the early summer of 2007, a particularly severe bloom caused a drinking water crisis for 4.43 million people in Wuxi city ${ }^{17,18}$.

Meiliang Bay, in the north of the lake is known as one of the most seriously eutrophic areas of Taihu ${ }^{19}$. Cyanobacteria amassing at the water surface are easily blown into littoral 
zones and in summer, prevailing southerly and southwesterly winds encourage toxic microcystis blooms to accumulate ${ }^{20,21}$ in the bay, where their impact varies depending on the predominant vegetation type. However, these zones have been relatively neglected by previous studies investigating the effects of blooms on local environmental parameters such as nutrient levels. Indeed, most of the studies have been based on laboratory trials or work in other field locations. A study of bloom accumulation in the littoral zone of Taihu lake is an essential step towards more reliable bloom forecasts and subsequent risk assessments for water supplies.

The objective of the present study is to establish the extent of bloom accumulation in different littoral aquatic plant zones of lake Taihu and to track the resulting responses in nitrogen and phosphorus levels. We attempt to explain the relationship between bloom accumulation and observed trends in a variety of physico-chemical environmental parameters. This study will inform local government management practice by helping to predict and mitigate the impact of future blooms on water quality in Taihu lake and in similar lakes elsewhere.

\section{EXPERIMENTAL}

Sample collection: Study was conducted in Meiliang Bay, a large, semi-enclosed bay and one of the most hyper-eutrophic parts of lake Taihu. Meiliang Bay is located in the northern region of the lake and has an average depth of $1.8 \mathrm{~m}$. Intensive cyanobacterial blooms often cover the whole area from June to September ${ }^{8}$. The experiment was performed at a field station of the Taihu Laboratory for Lake Ecosystem Research (TLLER, $\left.31.40^{\circ} \mathrm{N}, 120.22^{\circ} \mathrm{E}\right)^{22}$, located in the southeast of Meiliang Bay, where blooms usually persist for the whole summer.

On September 24, 2012, the onset of a massive Microcystis bloom was observed at the TLLER field station at Meiliang Bay. Three observation sites were chosen for monitoring bloom-nutrient interactions, as shown in Fig. 1. The open zone (A), located $240 \mathrm{~m}$ offshore, was characterized by an absence of any macrophyte vegetation. The floating plant zone (B) lay between 30 and $120 \mathrm{~m}$ offshore and had at least $80 \%$ surface coverage by species including native Trapa bispinosa and Nymphoides peltatum. The emergent plant zone (C) occupied a strip just 10-20 m wide, close to the shore and was dominated by another Taihu native, Phragmites australis.

In the early phase of the study between September 25 and 30,2012, the potential speed of bloom mat transport meant that adequate monitoring required water samples to be collected four times a day, at 6:00, 11:00, 16:00 and 21:00 h. Later on sampling was reduced to once every three days from October 2 to 13, 2012. Water from the surface layer $(20 \mathrm{~cm}$ depth) and bottom layer ( $20 \mathrm{~cm}$ above bottom sediment) was sampled for nutrient and chlorophyll $a(\mathrm{Chl}-a)$ analysis. Water temperature, $\mathrm{pH}$, dissolved oxygen (DO) and turbidity (TUR) were measured in situ using a multi-parameter water quality Sonde 6600 (Yellow Springs Instruments, USA). Data pertaining to solar radiation, wind direction and wind speed during the observation period were obtained from the TLLER meteorological station.

Analytical methods: Chemical parameters including total nitrogen (TN), total dissolved nitrogen (DTN), ammonium

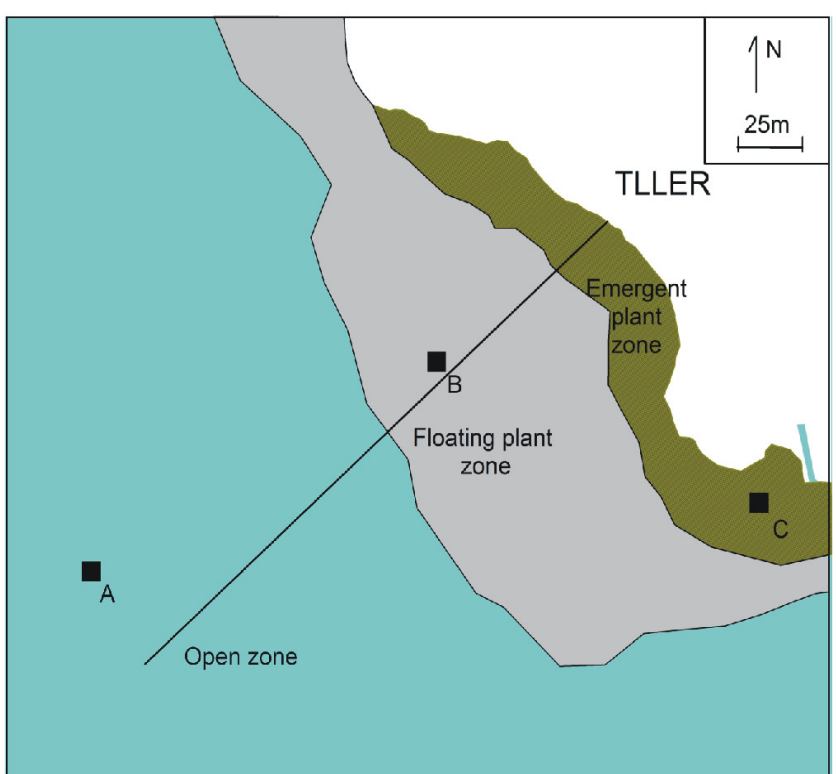

Fig.1. Observation sites in Lake Taihu

$\left(\mathrm{NH}_{4}-\mathrm{N}\right)$, nitrate $\left(\mathrm{NO}_{3}-\mathrm{N}\right)$, total phosphorus $(\mathrm{TP})$, total dissolved phosphorus (DTP), soluble reactive phosphorus (SRP) and chlorophyll- $a(\mathrm{Chl}-a)$ were quantified in the laboratory according to standard methodologies. Samples were filtered through a membrane filter (GF/F, Whatman, UK) prior to analysis for total dissolved nitrogen, $\mathrm{NH}_{4}-\mathrm{N}, \mathrm{NO}_{3}-\mathrm{N}$, total dissolved phosphorus and soluble reactive phosphorus concentrations in water. Total nitrogen and total dissolved nitrogen were determined using the alkaline potassium persulfate digestion method in unfiltered and filtered water, respectively. $\mathrm{NH}_{4}-\mathrm{N}$ was determined by the Nessler's reagent colorimetric method. $\mathrm{NO}_{3}-$ $\mathrm{N}$ was analyzed using a Skalar $\mathrm{SAN}^{++}$flow injection analyzer with a detection limit of $0.2 \mathrm{mg} / \mathrm{L}$ (Skalar Co., Netherlands). total phosphorus and total dissolved phosphorus were determined using the molybdenum blue colorimetric method in unfiltered and filtered water respectively, after digestion with alkaline potassium persulfate and soluble reactive phosphorus was analyzed using the ammonium molybdate spectrophotometric method without digestion procedure. The concentration of chlorophyll- $a$ was determined photometrically at wavelengths of $665 \mathrm{~nm}$ and $750 \mathrm{~nm}$ after filtration on Whatman $\mathrm{GF} / \mathrm{F}$ glass filters and $24 \mathrm{~h}$ extraction in $90 \%$ hot acetone ${ }^{23}$. Chlorophyll- $a$ is a useful proxy for phytoplankton biomass across a broad trophic gradient of lakes and quantifying Chl$a$ levels is a widely accepted means of assessing the biogeochemical status of a water body ${ }^{24,25}$. Therefore, in this study, chlorophyll- $a$ values are used as an indicator of the severity of bloom accumulation.

Data treatment: All water quality data were handled using Microsoft Excel 2010. Principal component analysis (PCA) was performed on standardized data using CANOCO for Windows version 4.5. Correlation analysis and analysis of variance (ANOVA) were carried out using SPSS 18.0 statistical software packages for personal computers. Levels of significance are reported as non-significant $(\mathrm{P}>0.05)$, significant $(*, 0.05>\mathrm{P}>0.01)$ or highly significant $(* *, \mathrm{P}<0.01)$ for all tests. 
RESULTS AND DISCUSSION

Changes in physico-chemical and meteorological parameters: Hydrodynamic process is an important physical phenomenon, exerting a powerful influence on the distribution of phytoplankton biomass in shallow lakes ${ }^{26}$. Wind direction and wind speed are particularly influential ${ }^{21}$ and in Taihu, cyanobacterial mats are driven by prevailing winds to accumulate in coastal areas ${ }^{27}$. Studies of previous blooms (composed mainly of Microcystis) show that Chl- $a$ concentrations in areas affected by wind drift are up to five times greater than in areas where blooms comprise only cyanobacteria grown in situ ${ }^{28}$. Water temperature can have a significant effect on algal biomass, but during the observation period of this study, the weather was mostly fine, with only one short rain shower on the evening of October 5. The water temperature at different study sites varied only slightly during the experimental period, averaging $23.06{ }^{\circ} \mathrm{C}$ in the open zone, $22.87^{\circ} \mathrm{C}$ in the floating plant zone and $23.51{ }^{\circ} \mathrm{C}$ in the emergent plant zone. These differences were considered small enough that water temperature could be eliminated from further consideration in this study.

Fig. 2 shows wind direction, wind speed, dissolved oxygen and turbidity during the study. Based on changes in these parameters, the observation period was divided into four phases: (1) September 25-28: characterized by relatively consistent wind speed, averaging a moderate $3 \mathrm{~m} / \mathrm{s}$ and blowing predominantly from the southeast. Water turbidity declined slightly in all three zones during this period and dissolved oxygen concentrations were generally stable. (2) September 28-30: wind direction turned to the northwest and mean wind speed increased slightly to $3.2 \mathrm{~m} / \mathrm{s}$. This phase saw turbidity of surface and bottom water layers increase and dissolved oxygen concentration increase slightly, too. (3) October 1-7: characterized by low wind speed averaging $1.8 \mathrm{~m} / \mathrm{s}$. Both dissolved oxygen concentration and turbidity showed decreasing trends in this period. (4) October 8-13: average wind speed picked up to a moderate $2.6 \mathrm{~m} / \mathrm{s}$, but varied in direction blowing predominantly northwesterly from October 10-12, but mainly southeasterly at other times. dissolved oxygen concentration and turbidity were once again generally stable.

Dissolved oxygen concentration and turbidity in both surface and bottom layers was seen to vary significantly between different littoral vegetation zones. Dissolved oxygen concentration was highest in open water zone, averaging 8.97 and $7.84 \mathrm{mg} / \mathrm{L}$ in surface and bottom layers, respectively, followed by the emergent plant zone where surface and bottom dissolved oxygen averaged 3.71 and $3.05 \mathrm{mg} / \mathrm{L}$, respectively. Dissolved oxygen levels were lowest in the floating plant zone, averaging just 2.98 and $0.81 \mathrm{mg} / \mathrm{L}$ in the surface and bottom water layers respectively. Photosynthesis of phytoplankton and physical mixing are the main increasing factors increasing dissolved oxygen levels in water during a bloom, while organic decay is the main factor acting to reduce dissolved oxygen. Where the water surface is shaded by floating-leaved vegetation, algal photosynthesis is limited. However, surface cover has relatively little impact on the decomposition process and since water in the floating plant zone experiences less hydrodynamic disturbance, it tends to become hypoxic or anaerobic. The disturbance caused by wind-wave action is much greater in the emergent plant zone than in the floating plant zone under the same wind field conditions. The average turbidities of surface and bottom water were 45.96 and 43.61 NTU in the emergent plant zone and this region yielded the highest turbidity values recorded in the study. The lowest turbidity values in the study were recorded in the floating plant zone, averaging 19.11 and 22.09 NTU in the surface and bottom layer, respectively.

Variation in Chl- $\boldsymbol{a}$ concentration: Temporal variations in Chl- $a$ concentration at the study sites in Meiliang Bay are shown in Fig. 3 and can be resolved into the four phases outlined below: (1) from September 25 to 28, wind conditions were not conducive to bloom accumulation in the area and Chl- $a$ concentrations show a gradually decreasing trend in both surface and bottom layers of all three zones. (2) From September 28 to 30 , winds remained moderate, but changed direction, becoming northwesterly and Chl- $a$ concentrations begin to increase overall. This could be taken as evidence that northwesterly winds favor bloom accumulation in the study area, were it not that Chl- $a$ levels register a decrease in the emergent plant zone at this time. This suggests that accumulation of bloom is less affected by wind direction and more closely related to wind speed. There is a distinct peak in Chl- $a$ value at 6:00 am, September 28, with a value of $241.99 \mu \mathrm{g} / \mathrm{L}$ in the emergent plant zone. (3) From October1 to 7, wind speed declines steadily, while Chl- $a$ level indicates an accumulation of cyanobacteria in all three zones, peaking on October 2. Low wind speeds do little to disperse or move the bloom on and thus favor accumulation in the study area. This is consistent with the conclusion of previous authors that small waves are conducive to algal growth and floating bloom accumulation ${ }^{29}$. Later, as wind speed increased, the bloom began to decline and Chl- $a$ concentration decreased overall. A significant decrease in Chl- $a$ concentrations was recorded on the evening of October 5 coinciding with a short rain shower. This is in line with previous studies identifying little or no precipitation as a precondition for bloom accumulation ${ }^{4}$. (4) From October 8 to 13, average wind speed was a moderate $2.6 \mathrm{~m} / \mathrm{s}$, swinging from southeasterly to northwesterly on October 10, then back again on October 12. The extent of bloom accumulation during this period was relatively stable, with little variation in Chl- $a$ values.

Diurnal trends in average Chl- $a$ concentrations in the littoral zone are shown in Fig. 4. Data from the open and floating plant zones show no statistically significant variation, though a slight increase in Chl- $a$ was observed at night (21:00) in the open zone, possibly as a result of reduced wind and wave action. Chl- $a$ levels in the floating plant zone also showed a slight increase in the afternoon (16:00), coinciding with peak intensity of solar radiation. Solar radiation supplies the primary energy for growth of autotrophic phytoplankton and the intensity of incident light also influences the rate of photosynthesis indirectly via other controlling factors ${ }^{30}$. dissolved oxygen concentration and plankton reproduction both increase markedly in the afternoon when solar radiation is strongest, enhancing bloom formation and boosting Chl- $a$ levels.

In the emergent plant zone, Chl- $a$ levels in both the surface and bottom water layers show clear daily fluctuations. The emergent plant zone is more susceptible to hydrodynamic disturbance than other zones and this is a likely reason for the dip in Chl- $\alpha$ concentration typically seen early in the day. This 

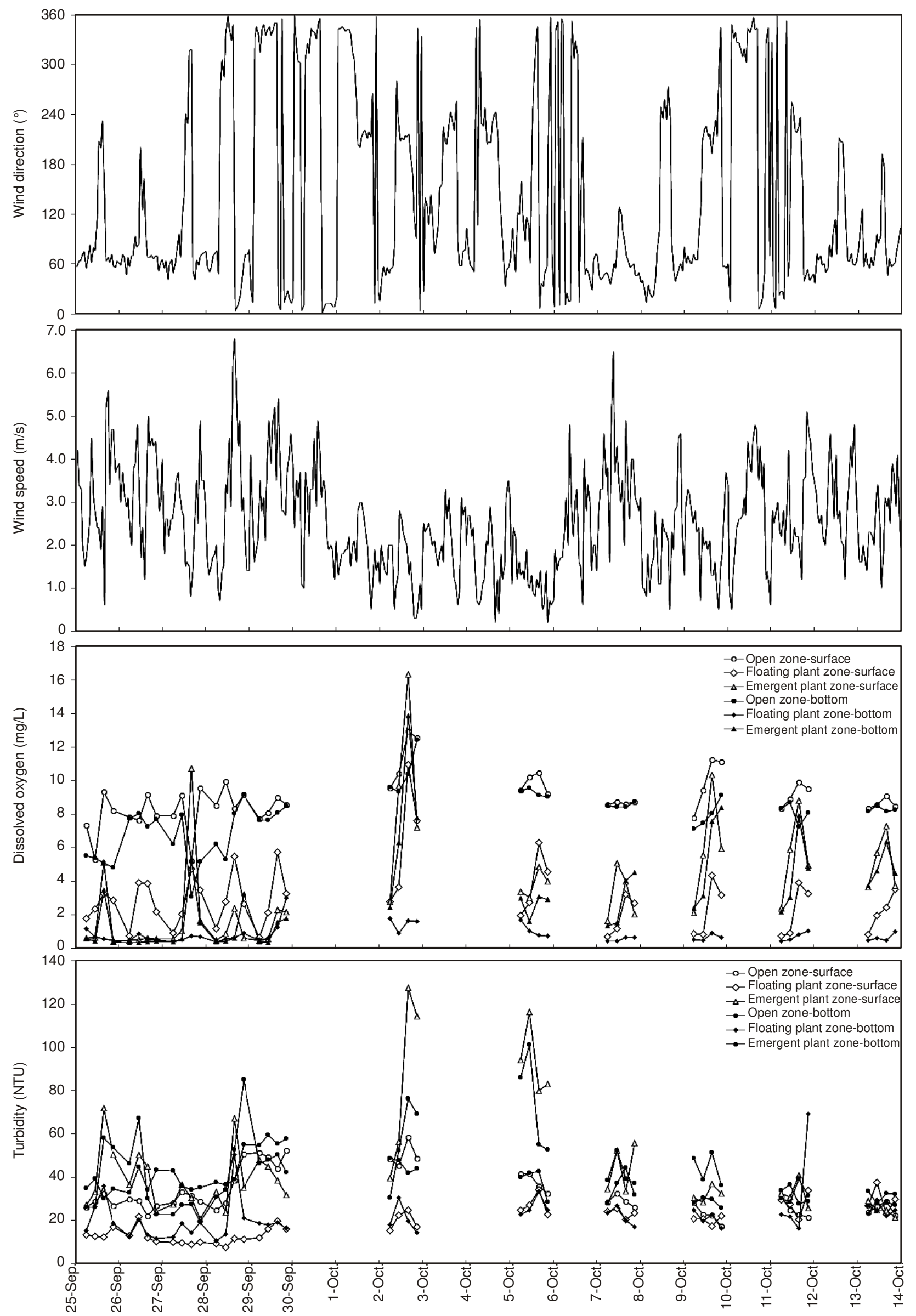

Fig. 2. Changes in wind direction, wind speed, dissolved oxygen and turbidity during the observation period 


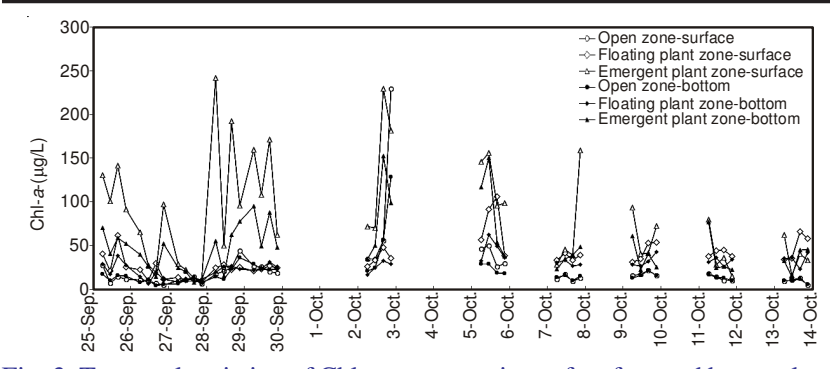

Fig. 3. Temporal variation of Chl- $a$ concentrations of surface and bottom layer

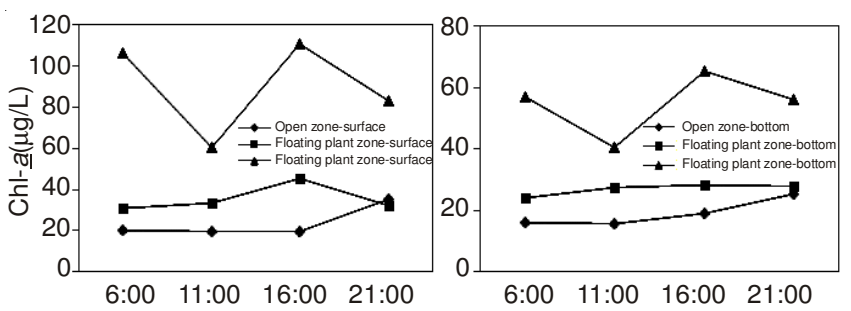

Fig. 4. Diurnal variation in average Chl- $a$ concentrations in different littoral vegetation zones

negative effect is subsequently overridden by the increasing influence of solar radiation and enhanced dissolved oxygen levels, both of them benefit phytoplankton growth and reproduction and boost Chl- $a$ levels. At the end of the day, Chl- $a$ concentration decreases again as solar radiation and hydrodynamic disturbance both decline, limiting dissolved oxygen content and phytoplankton growth and reducing the extent of bloom accumulation.

Chlorophyll- $a$ values in the surface and bottom water layers differed considerably between different vegetation zones. Average Chl- $a$ concentrations in the emergent plant zone were higher than elsewhere, at 84.28 and $49.51 \mu \mathrm{g} / \mathrm{L}$ in surface and bottom waters respectively, reflecting a differential ability to trap algal blooms. In the floating plant zone, average Chl- $a$ levels in surface and bottom waters were 35.59 and $26.98 \mu \mathrm{g} / \mathrm{L}$, respectively, while the lowest Chl- $a$ levels were recorded in the open zone, averaging 23.76 and $19.03 \mu \mathrm{g} / \mathrm{L}$ in surface and bottom layers respectively. One reason for the enhanced accumulation of Chl- $a$ in the emergent plant zone is distance to the shore while different patterns of hydrodynamic disturbance also play an important role in bloom capture.

Variation in nutrient concentration: Nitrogen and phosphorus are important nutrients for lake algal blooms. Trends of concentration in different forms of nutrient elements in both surface and bottom waters were studied. Trends for both total nitrogen and total phosphorus track those of Chl- $a$ in all three sites, increasing as the bloom accumulates. This is consistent with previous results ${ }^{27,31}$.

Trends in total dissolved phosphorus and soluble reactive phosphorus contents followed similar patterns, distinct from that of total phosphorus levels. A peak in total dissolved phosphorus and soluble reactive phosphorus on the first day was followed by a decline, most apparent in the emergent plant zone, may be due to rapid consumption of soluble phosphorus and the huge accumulation of fresh Microcystis in the area. Later in the study, total dissolved phosphorus and soluble reactive phosphorus contents stabilized, with slight fluctuations.

Total dissolved nitrogen content of surface and bottom waters was relatively high from September 25 to 29 , suggesting that in the early stages of accumulation, the bloom itself was the source of total dissolved nitrogen. Levels of total dissolved nitrogen content began to decrease thereafter, but the overall decline was very small, much less than that observed in total dissolved phosphorus levels in this phase of the study. Consumption of phosphorus is faster than that of nitrogen, a disparity that may be related to nitrogen fixation by cyanobacteria. In the early days of the study, $\mathrm{NH}_{4}-\mathrm{N}$ content is relatively high, with fluctuations that may be related to the release of ammonia from sediment and relatively strong denitrification processes. Later on, $\mathrm{NH}_{4}-\mathrm{N}$ levels declined slightly, perhaps as a result of microbial activity and adsorption. $\mathrm{NO}_{3}-\mathrm{N}$ levels in surface and bottom layers decreased significantly up until October 9, especially during September 25 to 29 , tracking the trend in dissolved oxygen concentration. $\mathrm{NO}_{3}-$ $\mathrm{N}$ concentrations then stabilized later in the observation period, except for a significant peak on October 11, which was followed by further decline.

Total phosphorus and total dissolved phosphorus concentrations in both surface and bottom water layers of the emergent plant zone peaked dramatically in the early phase of the observation and were significantly higher than in either the floating plant or open zones before October 5, but declined rapidly thereafter. Levels of both total phosphorus and total dissolved phosphorus remained relatively stable in the other two zones, but floating plant and open water zones differed from each other in that total phosphorus levels in the open zone were lower than in the floating plant zone, while, but total dissolved phosphorus content was the higher. From October 7, the dramatic decline in total dissolved phosphorus in the emergent plant zone meant that the open zone then had the highest total dissolved phosphorus levels of any zone. soluble reactive phosphorus levels in the floating plant zone were significantly lower than in the other two regions, but increased around October 11.

The spatial variation in total nitrogen and total dissolved nitrogen levels was similar to that seen for total phosphorus and total dissolved phosphorus. The $\mathrm{NH}_{4}-\mathrm{N}$ concentration in the emergent plant zone peaked from September 25 to 29, but remained stable in the open and floating plant zones and levels in all three regions were broadly consistent after that. $\mathrm{NO}_{3}-\mathrm{N}$ concentrations in all three regions followed a similar pattern, with no obvious variation during the observation period.

Factors controlling water quality in the littoral zone: The control of water quality in littoral zones of shallow lakes is highly complex, but identifying the principal factors is an essential step towards effective and environmentally appropriate management of water resources.

Principal component analysis has proved a useful technique in previous water quality studies and was used here to identify significant characteristics of the water quality in the studied water bodies.

The first three principal components (PCs) extracted by our analysis explained $79 \%$ of total variance in the raw data (Table-1). In particular, PC1 (44\%) was associated with changes in total phosphorus, total dissolved phosphorus, total nitrogen, total dissolved nitrogen, $\mathrm{NH}_{4}-\mathrm{N}$ and $\mathrm{Chl}-a$, with correlation coefficients exceeding 0.70 . These parameters are mainly a reflection of eutrophic index, implicating nutrient 


\begin{tabular}{lccc}
\hline \multicolumn{4}{c}{ TABLE-1 } \\
\multicolumn{3}{c}{ COMPONENT MATRIX FOR PRINCIPAL } \\
COMPONENT ANALYSIS
\end{tabular}

levels as principal factors in Chl- $a$ concentration and therefore in bloom accumulation. However, the spatial distribution of nutrients within the lake is almost as important as overall nutrient quantity and re-distribution processes have an important influence on local bloom accumulation. PC2 (20\%) was characterized by turbidity, indicating that hydrodynamic disturbance plays a part in controlling nutrient levels, but that the influence of wind and waves is less significant than that of the bloom itself. PC3 (16\%) was associated mainly with dissolved oxygen and soluble reactive phosphorus. Elevated dissolved oxygen may influence the release of phosphorus from the sediment. Peak consumption of dissolved oxygen takes place after the main phase of bloom accumulation, as decay sets in. Overall, variance of $\mathrm{PC} 1$ contribution rate is much higher than that of $\mathrm{PC} 2$ and $\mathrm{PC} 3$, indicating that the bloom process is the most significant influence on lake water quality in the littoral zone.

Effects of aquatic vegetation on accumulation of microcystis blooms: In ecologically balanced lakes the littoral zone is typically divided into three bands, characterized by macrophyte vegetation type. Moving offshore from the bank, we first see emergent plants, followed by a zone of floating-leaved macrophyte and then submerged macrophytes, beyond which lies open water ${ }^{32}$. Macrophytes contribute significantly to the primary production of lake littoral zones, supporting both detritivorous and herbivorous components of food webs ${ }^{33}$. Aquatic vegetation can also take up large quantities of nutrient from the environment, which is subsequently released as the plants decay. Aquatic macrophytes can undoubtedly play a significant role in the mechanics of bloom accumulation in eutrophic lakes, but vary in their ability to capture blooms.

The extent to which algal blooms accumulate in the different littoral zones of lake Taihu varied significantly, with the fastest and largest accumulations recorded in the emergent plant zone, where Chl- $a$ concentrations averaged at $84.28 \mu \mathrm{g} / \mathrm{L}$. Mean Chl- $a$ concentrations in the floating plant and open zones were 35.59 and $23.76 \mu \mathrm{g} / \mathrm{L}$, respectively. Thus, taking average Chl- $a$ concentration as a proxy for bloom accumulation, we see that the emergent plant zone has about 2.5 times the bloom capture capability of the floating plant zone and about 3.5 times that of the open zone. The results show that blooms will accumulate first in vegetated regions and that accumulations will be greatest in the emergent plant zone $(\mathrm{P}=0.01)$. The difference between the floating plant zone and open zone is also significant $(\mathrm{P}<0.05)$, reflecting that blooms accumulate more readily in vegetated areas than in open water. In summary, effect of aquatic vegetation on bloom accumulation is significant and the effect of emergent macrophytes is greater than that of floating plants.

However, the retention of blooms in different vegetation zones is also different. Cyanobacteria accumulate easily in the emergent plant zone, but they can also be dispersed more rapidly than blooms in the floating plant zone. Blooms accumulate more slowly among floating plants than among emergent vegetation, but are also more resistant to dispersal, meaning the accumulation persists for longer. For example, in the early phase of the bloom observation, average Chl- $a$ levels in surface waters of the emergent plant zone were 116.25 and $18.55 \mu \mathrm{g} / \mathrm{L}$ on September 25 and 27, respectively, while on the same dates average Chl- $a$ concentrations in the floating plant zone were 36.86 and $10.67 \mu \mathrm{g} / \mathrm{L}$, respectively. These data represent a decline in surface Chl- $a$ levels of 84 and $71.1 \%$ in the emergent plant and floating plant zones, respectively. For the bottom water layers, these decline proportions were 71.5 and $66.5 \%$, respectively. This study shows that blooms in the floating plant zone can be expected to persist longer than those in the emergent plant zone. Since bloom decay can foster harmful 'black spot' events, accurate estimates of retention times may be crucial in predicting and mitigating the impact of bloom events ${ }^{31}$.

Response of water quality to microcystis bloom accumulation: Accumulation of cyanobacterial blooms has direct and indirect impacts on a variety of water quality parameters including dissolved oxygen content, turbidity, nutrient content, etc. Variation in dissolved oxygen and nutrient levels may affect the growth and decay of cyanobacteria, which can in turn lead to further changes in dissolved oxygen and nutrient content ${ }^{31}$. Bloom accumulation also imposes significant effects on hydrodynamic disturbance, the extent of which is reflected in changes in water turbidity. Hydrodynamic disturbance is an important factor for cyanobacterial growth and has been previously shown to have a strong effect on nutrient concentration in shallow lakes $^{26,34}$. Previous studies in lake Taihu have demonstrated an influence of hydrodynamic forces on cyanobacterial growth ${ }^{35}$ and it has been reported elsewhere that disturbance is also a factor in the impact of cyanobacterial decomposition in lakes ${ }^{36}$.

Correlation analysis between Chl- $a$ concentration and water quality in different littoral vegetation zones in Lake Taihu was performed by SPSS 18.0 statistical software. Pearson correlation coefficients and two-tailed test results are shown in Table-2. It was found that turbidity correlated positively with Chl- $a$ concentrations in the surface and bottom layers of all three zones and that the correlation was most significant in surface waters $(\mathrm{P}<0.01)$. Turbidity was most significantly affected by bloom accumulation in the emergent plant zone and the effect was smaller in open water than in either of the vegetated zones.

Correlation analysis also showed that in open water, dissolved oxygen contents of both surface and bottom layers were significantly positively correlated with Chl- $a$ concentration. The correlation of dissolved oxygen to Chl- $a$ in the floating plant zone was not significant, which reflects that dissolved oxygen levels there were less influenced by bloom 


\begin{tabular}{|c|c|c|c|c|c|c|}
\hline \multicolumn{7}{|c|}{$\begin{array}{c}\text { TABLE-2 } \\
\text { CORRELATION BETWEEN CONCENTRATION OF Chl- } a \text { AND WATER QUALITY PARAMETERS }{ }^{1} \text { ) }\end{array}$} \\
\hline \multirow{2}{*}{ Parameters } & \multicolumn{2}{|c|}{ Open zone } & \multicolumn{2}{|c|}{ Floating plant zone } & \multicolumn{2}{|c|}{ Emergent plant zone } \\
\hline & Surface & Bottom & Surface & Bottom & Surface & Bottom \\
\hline Dissolved oxygen & $0.517^{* *}$ & $0.572^{* *}$ & 0.215 & 0.122 & 0.009 & 0.226 \\
\hline Turbidit & $0.478^{* *}$ & $0.305^{*}$ & $0.599^{* *}$ & $0.364^{*}$ & $0.612^{* *}$ & $0.429^{*}$ \\
\hline Total phosphorus & $0.983^{* *}$ & $0.959^{* *}$ & $0.735^{* *}$ & $0.595^{* *}$ & $0.838^{* *}$ & $0.706^{* *}$ \\
\hline Total dissolved phosphorus & -0.255 & -0.235 & 0.182 & 0.159 & -0.053 & -0.122 \\
\hline Soluble reactive phosphorus & -0.288 & -0.287 & -0.008 & -0.225 & -0.097 & -0.233 \\
\hline Total nitrogen & $0.982^{* *}$ & $0.966^{* *}$ & $0.784^{* *}$ & $0.648^{* *}$ & $0.856^{* *}$ & $0.717^{* *}$ \\
\hline Total dissolved nitrogen & -0.094 & -0.105 & 0.230 & -0.065 & 0.039 & 0.008 \\
\hline $\mathrm{NH}_{4}-\mathrm{N}$ & 0.166 & $0.356^{*}$ & 0.254 & $0.314^{*}$ & 0.056 & 0.067 \\
\hline $\mathrm{NO}_{3}-\mathrm{N}$ & -0.243 & -0.218 & -0.051 & -0.132 & -0.070 & $-0.357^{*}$ \\
\hline
\end{tabular}

accumulation. The influence blooms on dissolved oxygen levels in the emergent and floating plant zones are greater than in the open zone, possibly as a result of the opposing influences of different bloom phases on dissolved oxygen, whereby photosynthesis rates and dissolved oxygen strongly increase during the accumulation phase, but oxygen is rapidly consumed during decomposition, especially at night time.

This study showed that is the accumulation of cyanobacterial blooms is responsible for elevated total nitrogen and total phosphorus levels. As shown in Table-2, total nitrogen and total phosphorus contents of surface and bottom waters are obviously influenced by bloom accumulation in all three regions and that the correlation is most significant in surface waters $(\mathrm{P}<0.01)$. Increasing availability of total nitrogen and total phosphorus then further encourages bloom development. A previous study has indicated that algal blooms might also contribute to increased levels of in particulate phosphorus ${ }^{27,37}$.

Correlation analyses also showed that dissolved nutrients (total dissolved phosphorus, soluble reactive phosphorus, total dissolved nitrogen, ammomium $\mathrm{NH}_{4}-\mathrm{N}$ and nitrate $\mathrm{NO}_{3}-\mathrm{N}$ ) in surface and bottom layers are also correlated with Chl-a concentration in all three littoral zones. From Table-2, we see that soluble reactive phosphorus and $\mathrm{NO}_{3}-\mathrm{N}$ content correlate negatively with Chl- $a$ level and the effect is more obvious in the bottom layer of the vegetated zones than in surface waters. This suggests that the accumulating blooms absorb soluble reactive phosphorus and $\mathrm{NO}_{3}-\mathrm{N}$, especially from the bottom layer. Chl- $a$ values showed some positive correlation with $\mathrm{NH}_{4}$ $\mathrm{N}$ in the three regions, indicating that bloom accumulation leads to elevated of $\mathrm{NH}_{4}-\mathrm{N}$ levels and again the effect is most obvious in the bottom layer. This may be explained by a release of sediment $\mathrm{NH}_{4}-\mathrm{N}$ and the bacterial mineralization of organic substances back to $\mathrm{NH}_{4}-\mathrm{N}$.

In summary, the accumulation of cyanobacterial blooms has a pronounced effect on water quality, leading to changes in levels of several important nutrients. Changes in total nitrogen, total phosphorus, total dissolved phosphorus and soluble reactive phosphorus are most obvious in the emergent plant zone, while total dissolved nitrogen, $\mathrm{NH}_{4}-\mathrm{N}$ and $\mathrm{NO}_{3}-\mathrm{N}$ concentrations change more significantly in the floating plant zone. Moreover, the diffusion of accumulated nutrients from the emergent plant zone is faster than from the floating plant zone, meaning highly enriched conditions are more likely to form the floating plant zone, especially with respect to dissolved nutrients. Bloom retention has an obvious positive influence on dissolved oxygen levels in the latter phases of a bloom event and phosphorus levels also increase for a period of 2-3 days. The effect lasts longer in the floating plant zone than in the emergent plant zone. This study shows that decomposing blooms produce different effects on dissolved oxygen and nutrient levels in different aquatic vegetation zones.

\section{Conclusion}

Floating Microcystis blooms are very apt to accumulate in the vegetated margins of shallow lakes such as Taihu lake, a process that rapidly transports large quantities of nutrient to the littoral zone. The extent to which floating Microcystis blooms accumulate in different aquatic vegetation zones differs considerably. The emergent plant zone has a relatively higher bloom capture capability than the floating plant zone, but bloom retention is greater in the floating plant zone. Massive blooms are thus more likely to decompose in the floating plant zone, leading to a significant decrease in dissolved oxygen levels. The floating plant zone of Taihu lake and potentially of similar shallow eutrophic lakes, is thus a higher risk of fostering "black spot" events than the emergent plant zone. Vegetation type and the spatial distribution of incipient blooms in the littoral zone are therefore important considerations in evaluating the risk of catastrophic algal blooms.

\section{ACKNOWLEDGEMENTS}

The authors thank the TLLER for providing the meteorological data and field observatory facilities. The authors also appreciated the assistance of Wei Zhang, Jingchen Xue and Jianming Deng in the data analysis. This work was supported by the National Natural Science Foundation of China (Grant No. 41171368, 41230744), the Institute of Geography and Limnology (NIGLAS2012135002) and the National Water Pollution Control and Treatment Technology Special Program of China (2012ZX07101-010).

\section{REFERENCES}

1. V.H. Smith, Environ. Sci. Pollut. Res., 10, 126 (2003).

2. M.M. Marinho and S.M.F. de Oliveira e Azevedo, Aquat. Ecol., 41, 525 (2007).

3. L. Wang, Q.H. Cai, L. Tan and L.H. Kong, Sci. Total Environ., 409, 3820 (2011).

4. M.W. Wang, Q.X. Xu, Y. Che and K. Yang, Huadong Shifan Daxue Xuebao (Nat. Sci.), 1, 21 (2011). 
5. X. Liu, X.H. Lu and Y.W. Chen, Harmful Algae, 10, 337 (2011).

6. H.T. Duan, R.H. Ma, X.F. Xu, F.X. Kong, S.X. Zhang, W.J. Kong, J.Y. Hao and L.L. Shang, Environ. Sci. Technol., 43, 3522 (2009).

7. K.T.M. Wong, J.H.W. Lee and P.J. Harrison, Harmful Algae, 8, 407 (2009).

8. Y.W. Chen, B.Q. Qin, K. Teubner and M.T. Dokulil, J. Plankton Res., 25, 445 (2003)

9. T.G. Otten, H. Xu, B.Q. Qin, G.W. Zhu and H.W. Paerl, Environ. Sci. Technol., 46, 3480 (2012).

10. A. de Kluijver, J. Yu, M. Houtekamer, J.J. Middelburg and Z. Liu, Limnol. Oceanogr., 57, 1245 (2012).

11. L. Zhang, K. Li, Z. Liu and J.J. Middelburg, Limnol. Oceanogr., 55, 1912 (2010).

12. A. Pereira, B. Tassin and S.E. Jorgensen, Ecol. Modell., 75-76, 447 (1994).

13. W. Wang, C. Yin, Y. Wang and J. Lu, Atmos. Environ., 40, 5522 (2006).

14. H.W. Paerl, Estuaries Coasts, 32, 593 (2009).

15. S.W. Wilhelm, S.E. Farnsley, G.R. LeCleir, A.C. Layton, M.F. Satchwell, J.M. DeBruyn, G.L. Boyer, G.W. Zhu and H.W. Paerl, Harmful Algae, 10, 207 (2011).

16. B.Q. Qin, P.Z. Xu, Q.L. Wu, L.C. Luo and Y.L. Zhang, Hydrobiologia, 581, 3 (2007)

17. M. Yang, J.W. Yu, Z. Li, Z.H. Guo, M. Burch and T.F. Lin, Science, 319, 158 (2008).

18. B.Q. Qin, G.W. Zhu, G. Gao, Y.L. Zhang, W. Li, H.W. Paerl and W.W. Carmichael, Environ. Manage., 45, 105 (2010).

19. M. Zhang, Z.Q. Wang, J. Xu, Y.Q. Liu, L.Y. Ni, T. Cao and P. Xie, Chemosphere, 82, 329 (2011).

20. F.Z. Chen, X.L. Song, Y.H. Hu, Z.W. Liu and B.Q. Qin, Ecol. Eng., 35 1637 (2009).

21. Y. Li, C. Tang, C. Wang, D.O. Anim, Z. Yu and K. Acharya, Ecol. Eng., 51, 104 (2013).

22. H. Xu, H.W. Paerl, B.Q. Qin, G.W. Zhu and G. Gao, Limnol. Oceanogr., 55, 420 (2010).
23. Y.W. Chen, K.N. Chen and Y.H. Hu, J. Lake Sci., 18, 550 (2006).

24. P. Kasprzak, J. Padisák, R. Koschel, L. Krienitz and F. Gervais, Limnologica, 38, 327 (2008).

25. W.J. Moses, A.A. Gitelson, R.L. Perk, D. Gurlin, D.C. Rundquist, B.C. Leavitt, T.M. Barrow and P. Brakhage, Water Res., 46, 993 (2012)

26. Y.Q. Ding, B.Q. Qin, G.W. Zhu, T.F. Wu, Y.P. Wang and L.C. Luo, Ecohydrology, 5, 798 (2012).

27. G.W. Zhu, F. Wang, G. Gao and Y.L. Zhang, Water Environ. Res., 80, 832 (2008).

28. H.J. Cai and W.M. Chen, in ed.: Q.M. Cai, Influence of Draft and Degradation of Microcystis Bloom on Water Environment of Lake Taihu. In: Ecological and Environmental Research of Lake Taihu. Meteorological Press, Beijing: pp. 149-157 (1998) (in Chinese).

29. X.J. Sun, B.Q. Qin and G.W. Zhu, J. Environ. Sci. (China), 28, 506 (2007).

30. L.Y. Yang, L.J. Jiang and B.Q. Qin, China Environ. Sci., 24, 572 (2004).

31. M.Y. Zhu, G.W. Zhu, L.L. Zhao, X. Yao, Y.L. Zhang, G. Gao and B.Q. Qin, Environ. Sci. Pollut. Res., 20, 1803 (2013).

32. B. Czeczuga, B. Mazalska, A. Godlewska and E. Muszynska, Limnologica, 35, 283 (2005).

33. D. Baldantoni, A. Alfani, P. Di Tommasi, G. Bartoli and A.V. De Santo, Environ. Pollut., 130, 149 (2004).

34. T.F. Wu, B.Q. Qin, G.W. Zhu, Y.Q. Ding, Y.P. Wang, L.C. Luo, W. Li and W.M. Zhang, Chin. J. Oceanology Limnol., 30, 796 (2012).

35. B.Q. Qin and C.X. Fan, China Environ. Sci., 22, 150 (2002). (in Chinese with English abstract).

36. M.G.M. Alam, N. Jahan, L. Thalib, B. Wei and T. Maekawa, Environ. Int., 27, 363 (2001).

37. W.M. Chen, X.F. Huang and W.P. Zhou, Lake Ecosystem Observation Methods, China Environmental Sciences Press, Beijing (2005) (in Chinese). 